\title{
Design a Uplink-Downlink Reconfigurable Patch Antenna for Modern Space Application
}

\author{
Naman Mehrotra ${ }^{1}$, Dr. K. M. Singh ${ }^{2}$, Shashibhushan Sharma ${ }^{3}$ \\ ${ }^{1}$ Assistant Professor at JECRC UDML College of Engineering, Jaipur \\ ${ }^{2}$ Professor at JECRC University, Jaipur, India \\ ${ }^{3}$ Assistant Professor at JECRC University, Jaipur, India
}

\begin{abstract}
In this paper, a modified elliptical reconfigurable patch antenna with stripline feed has been analyzed and simulated for the Modern satellite communication Applications. The overall size of the antenna is $60 \mathrm{~mm} \times 60 \mathrm{~mm} \times 1.59 \mathrm{~mm}$. The antenna has been operated on two different resonant frequency of $3.93 \mathrm{GHz}$ (downlink) and $6.15 \mathrm{GHz}$ (uplink) for satellite and application band on the basis of switching conditions. The simulated gain of antenna in the obtained frequency range is closed to $4.7 \mathrm{dBi}$ and $3.6 \mathrm{dBi}$ for $\mathrm{OFF}$ and $\mathrm{ON}$ conditions respectively. Maximum radiations are directed normal to patch geometry and shape of patterns is somewhat similar to a isotropic radiation pattern [4] as a dumble shape in the upper hemisphere. This reconfigurable patch antenna has been designed specifically for the application of satellite communication systems. The proposed antenna has been simulated by applying CST Microwave Studio Software.
\end{abstract}

Keywords: Reconfigurable, Compact, PIN-diode, CST Microwave

\section{Introduction}

A reconfigurable antenna can be considered as one of the key elements in future satellite communication transceivers. The benefits of using a reconfigurable antenna is the ability to operate in two different frequency bands where the total antenna volume can be reused thus enabling the overall size to be reduced. Devices using a single compact antenna allow reduction in the dimensions of the device and more space to integrate other electronic components.

In addition, reconfigurable antenna [3] can be a cheaper alternative to traditional adaptive arrays or they can be incorporated into adaptive arrays to improve their performance by providing additional degrees of freedom. Microstrip Patch antenna has played an important role in improving the performance and reducing the overall size of satellite devices by observing the inherent properties of patch antenna. Now a day antenna designers are modifying the conventional geometries, so that these may be applied in modern communication systems. It is realized that using a slot/slits in the patch geometry or modifications in substrate parameters improves the performance of antenna to a great extent but after reaching an optimum value, no feasible improvement in performance may be achieved. Pertaining to satellite communications, an uplink (UL or U/L) is the part of a communication link used for the transmission of signals from an Earth terminal to a satellite or to an airborne platform. A downlink (DL) is the link from a satellite to a ground station.

In recent times several single layer and rectangular geometry fed by microstrip line have been reported [1-2] which mainly resonate in higher frequency. In the present paper a compact reconfigurable patch antenna fed by strip line has been designed. A conventional patch antenna has been modified in several steps and radiation performances in each stage of modification are simulated using CST Microwave Studio Simulation Software.

\section{Antenna Design and Analysis of the Results}

The simple elliptical patch antenna [1] consists of a dielectric material FR4 lossy for substrate layer having dimensions $60 \times 60 \times 1.59 \mathrm{~mm}$. The simple elliptical patch antenna is shown in figure:
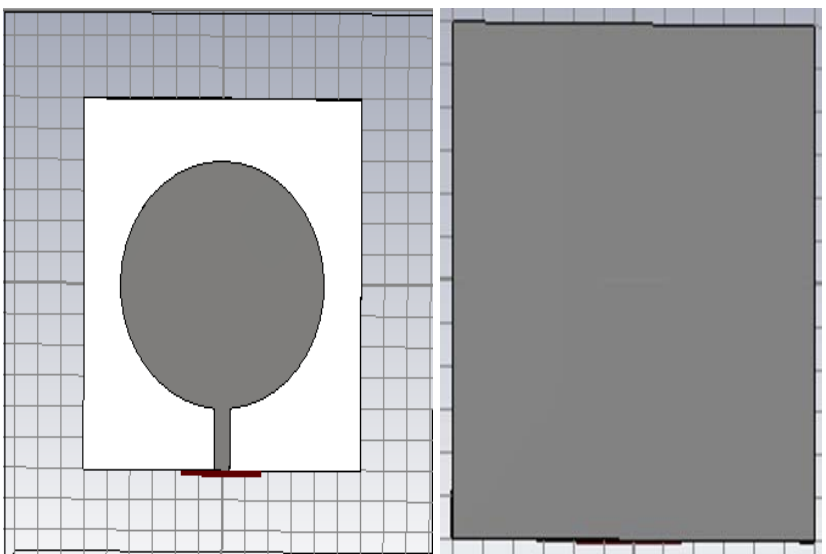

Figure 1: Top and Bottom view of Elliptical patch Antenna The results shown below, Relation between S- parameter magnitude in $\mathrm{dB}$ and frequency in $\mathrm{GHz}$, indicates that conventional elliptical patch antenna is resonating at 3.9835 $\mathrm{GHz}$ with narrow Impedance Bandwidth. 


\section{International Journal of Science and Research (IJSR)}

ISSN (Online): 2319-7064

Index Copernicus Value (2013): 6.14 | Impact Factor (2014): 5.611

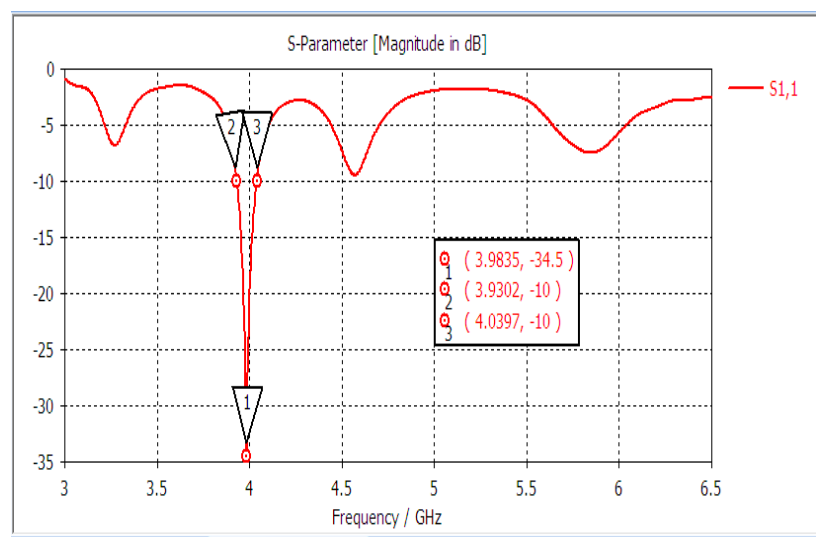

Figure 2: S-Parameter Vs Frequency

The figure 3 shows the relation between Standing Wave Ratio and Frequency. Result shown below, the Antenna SWR is 1.0384 which is less than 2 at resonating frequency $3.9835 \mathrm{GHz}$.

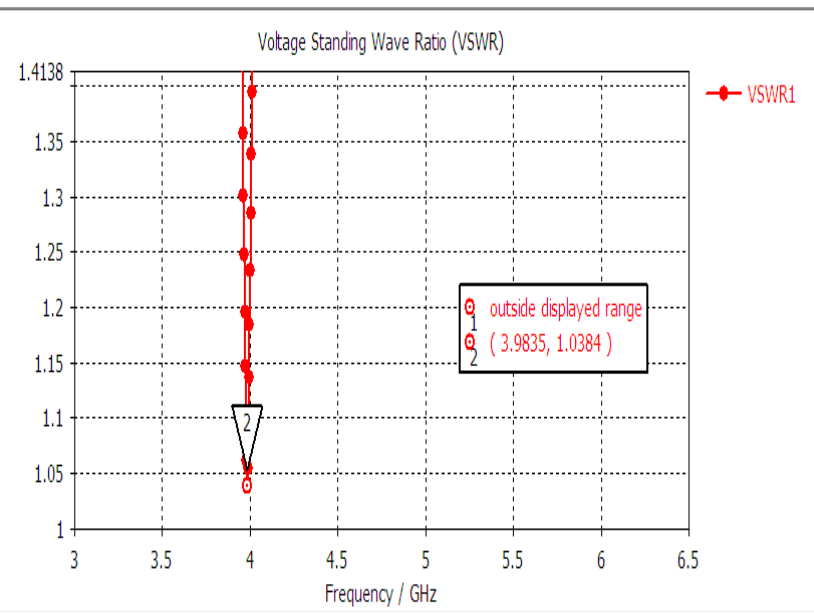

Figure 3: VSWR Vs Frequency

The figure 4 shows the impedance matching between patch and feed-line geometry. In this Smith chart graph, input impedance value of antenna at resonance frequency 3.985 $\mathrm{GHz}$ is $51.25 \mathrm{real},-1.437209 \mathrm{Ohm}$ which is close to $50 \mathrm{Ohm}$. In this way, a very good matching between the designed antenna structure and the few network has been achieved.

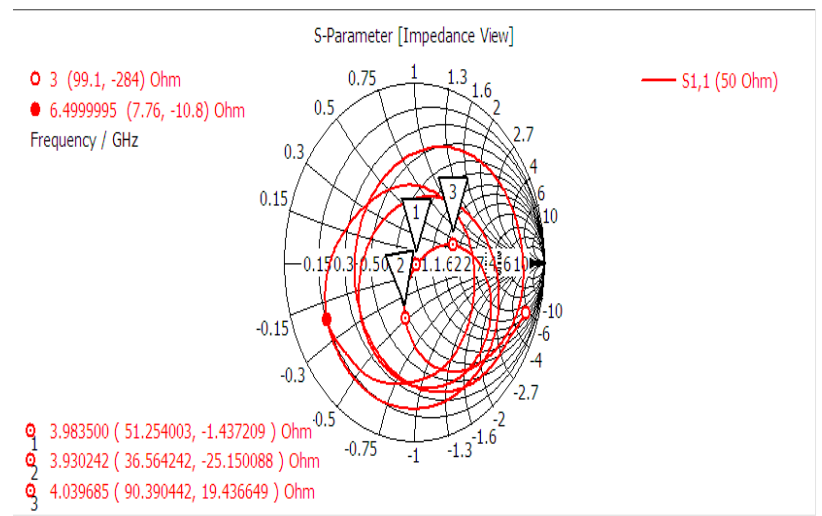

Figure 4: Smith Chart

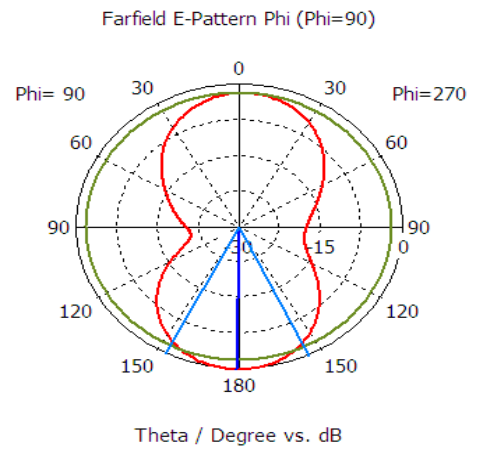

Figure 5: Radiation Pattern

Figure 5 shows the radiation pattern of Simple Elliptical patch Antenna similar to a dumble shape radiation pattern.

This is the discussion about the results of Simple Elliptical patch antenna. This basic antenna geometry is not suitable for frequency reconfiguration [5] [10]. Since cutting a slot [11] on the radiator, can change the current distribution and current path. In this design cut a rectangular slot size $15 \times 0.03 \mathrm{~mm}^{2}$ on the patch element as shown in figure 6 .

One PIN diode is placed on the rectangular slot [6-8] to patch element which has been used as a switch. The SMP1320-079LF series PIN Diode has parameters such as Isolation $20-40 \mathrm{~dB}$, Switching speed $650 \times 10^{-9}$, Bandwidth $20-2000 \mathrm{MHz}$, Working Voltage 3-5Volts, Bias current $10^{4}$ micro amp, Insertion Loss $0.5-1 \mathrm{~dB}$, Resistance 5.4-8.5ohm, Current 3.4nAmp-4.5pAmp, Operational capacitance 0.2$0.3 \mathrm{~F}$ and Size is $0.3 \times 0.3 \mathrm{~mm}^{2}$. PIN Diode In the reverse bias condition (OFF condition) the modified antenna geometry resonate on the higher side which reside on the uplink frequency band 5.9 to $6.2 \mathrm{GHz}$.

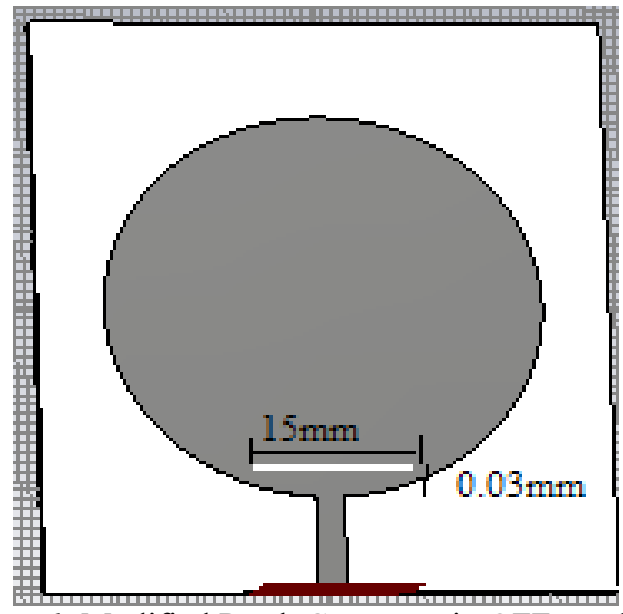

Figure 6: Modified Patch Geometry in OFF condition

This modified antenna geometry resonate at $6.15 \mathrm{GHz}$ frequency. The Antenna SWR is 1.4348 which is less than 2 at resonating frequency $6.15 \mathrm{GHz}$. The gain of modified antenna geometry is $4.7 \mathrm{dBi}$. This antenna geometry is suitable for satellite uplink application. 


\section{International Journal of Science and Research (IJSR) \\ ISSN (Online): 2319-7064}

Index Copernicus Value (2013): 6.14 | Impact Factor (2014): 5.611

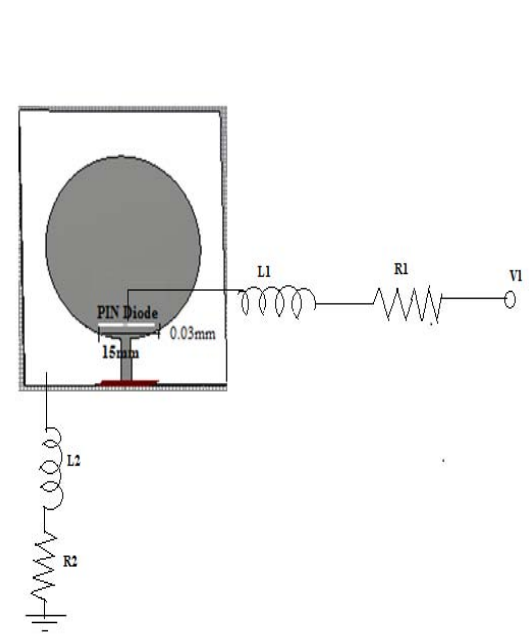

(a)

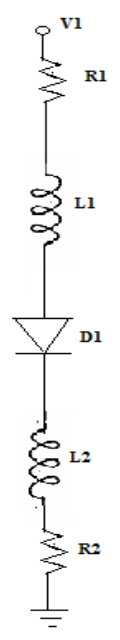

(b)

Figure 7: Circuit block diagram

Figure 7 shows the circuit diagram of Reconfigurable Antenna [11] in which the PIN Diode is connected with Inductors and Resistors. The PIN Diode is turned ON/OFF using a DC biased signal. The bias network for diode is shown in figure 7(b), where Inductors L1 and L2 are used as RF chokes to provide low impedance for DC signals and high impedance for RF signals. The resistors $\mathrm{R} 1$ and $\mathrm{R} 2$ are used to provide DC biasing current to PIN Diode.

In next condition PIN diode [9-10] works as a Forward bias (ON condition). Figure 8 shows the antenna geometry in the ON condition. In the Forward bias condition (ON condition), the modified antenna geometry resonate on the lower side which reside on the downlink frequency band 3.7 to $4.2 \mathrm{GHz}$.

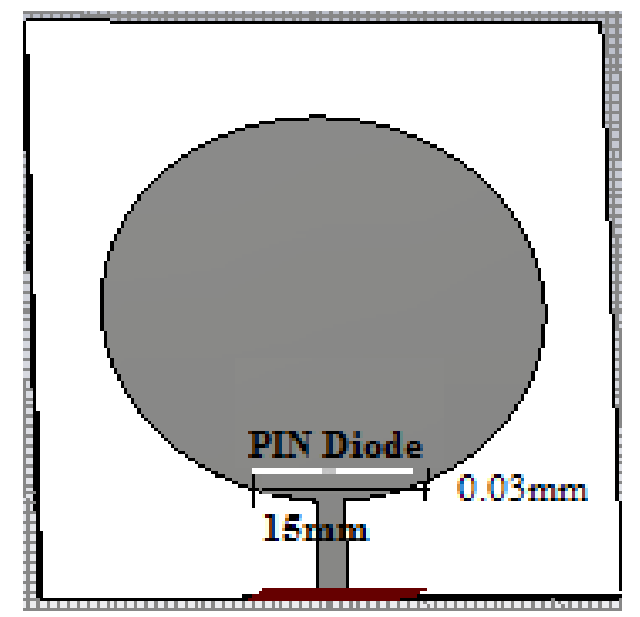

Figure 8: Modified Patch Antenna Geometry in ON condition

This modified antenna geometry resonates at $3.93 \mathrm{GHz}$ frequency. The Antenna SWR is 1.1254 which is less than 2 at resonating frequency $3.93 \mathrm{GHz}$. The gain of modified antenna geometry is $3.6 \mathrm{dBi}$. This antenna geometry is suitable for satellite downlink application.

Table1 shows the resonant frequencies in $\mathrm{ON}$ and $\mathrm{OFF}$ conditions.

Table 1: Resonant Frequencies in $\mathrm{ON}$ and OFF conditions

\begin{tabular}{|c|c|}
\hline The state of Switches & Resonant Frequencies $f(\mathrm{GHz})$ \\
\hline OFF & 6.15 \\
\hline ON & 3.93 \\
\hline
\end{tabular}

Table 2: antenna parameters in ON and OFF condition

\begin{tabular}{|c|c|c|}
\hline Parameter & ON & OFF \\
& F1 & F2 \\
\hline S- parameter & $-24.5 \mathrm{~dB}$ & $-14.91 \mathrm{~dB}$ \\
\hline VSWR & 1.124 & 1.438 \\
\hline Gain & $3.6 \mathrm{dBi}$ & $4.7 \mathrm{dBi}$ \\
\hline
\end{tabular}

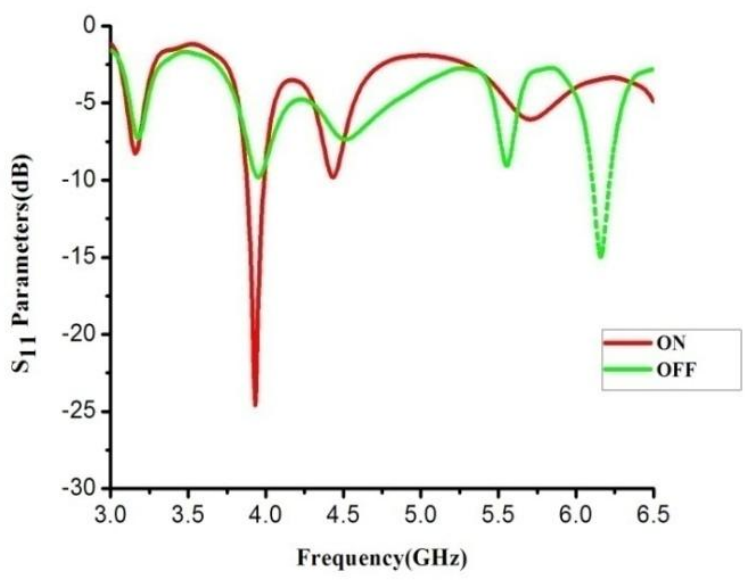

Figure 9: S-parameter in $\mathrm{ON}$ and off Condition

Figure 9 illustrates the relation between magnitude of $\mathrm{S}$ parameter $(\mathrm{dB})$ and frequency $(\mathrm{GHz})$. When Switch is OFF, then obtained resonance frequency is $6.15 \mathrm{GHz}$, means Reconfigurable antenna works at Uplink Frequency. When Switch is ON then obtained resonance frequency is 3.93, means Reconfigurable Antenna work at Downlink Frequency.

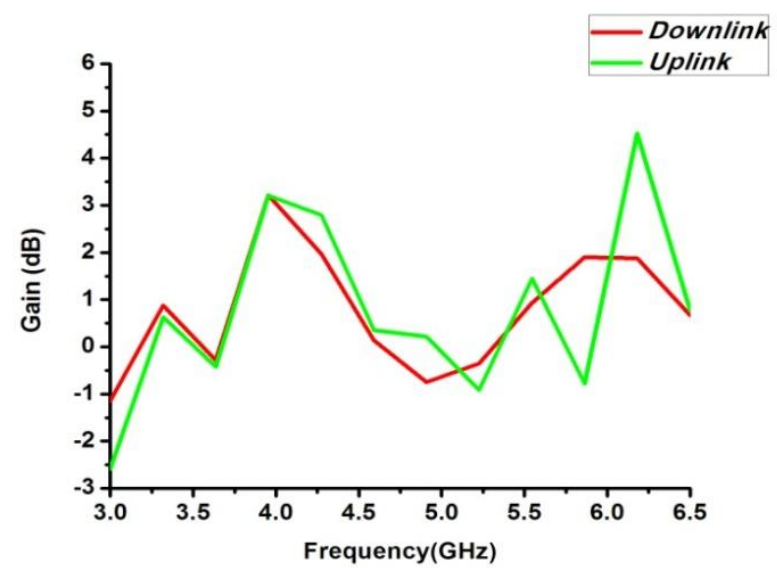

Figure 10: Gain Vs Frequency Graph in for Uplink and Downlink Frequencies

Figure 10 shows the relation between gain in $\mathrm{dB}$ and frequency. In this graph represent both $\mathrm{ON}$ and $\mathrm{OFF}$ condition. In first graph antenna work as a switching ON state, this condition is obtained gain is $3.6 \mathrm{dBi}$ at resonating 


\section{International Journal of Science and Research (IJSR) \\ ISSN (Online): 2319-7064}

Index Copernicus Value (2013): 6.14 | Impact Factor (2014): 5.611

frequency $3.93 \mathrm{GHz}$. In second graph antenna works as a Switching OFF state. For this condition, the obtained gain is $4.7 \mathrm{dBi}$ at resonating frequency $6.15 \mathrm{GHz}$.

Radiation Pattern is very important parameter for antenna. The far field radiation pattern of the Reconfigurable Antenna is similar to isotropic radiation pattern Figure 11 and 12 demonstrate the $\mathrm{ON}$ and $\mathrm{OFF}$ switching condition. The antenna radiation pattern looks like a dumble shape at Uplink $(6.15 \mathrm{GHz})$ and Downlink $(3.93 \mathrm{GHz})$.

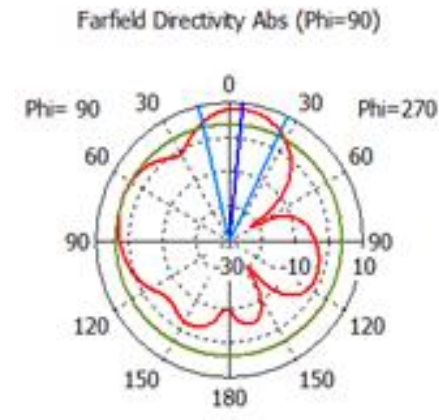

Frequency $=6.5$

Man lobe magnitude $=8.1 \mathrm{~dB}$ Man lobe drection $=6.0$ deg. Angular width $(3 \mathrm{~dB})=38.8 \mathrm{deg}$. Side bbe level $=-4.1$ d

Theta / Degree vs. dBi

Figure 11: Far Field Radiation Pattern in OFF mode

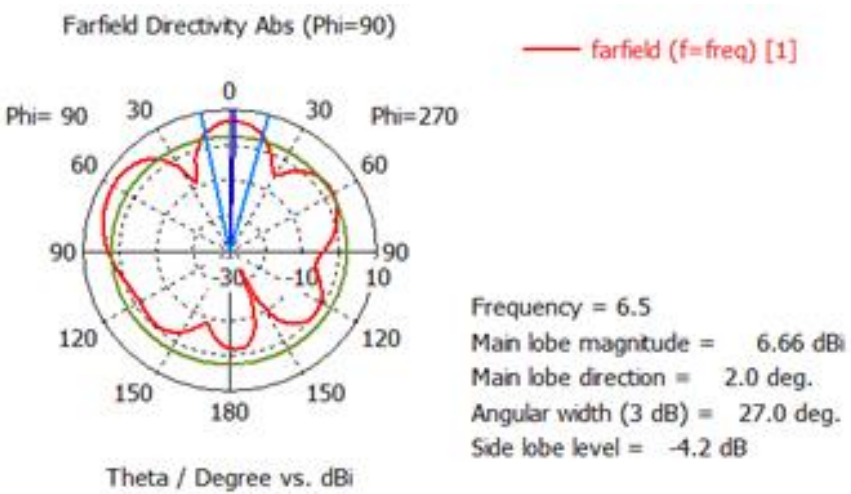

Figure 12: Far Field Radiation Pattern in ON mode

\section{Conclusion and Future Work}

This paper presents the design and performance of a modified reconfigurable elliptical patch antenna for satellite downlink-uplink application. The combined effect of modifications in patch geometry has significantly reconfigured the antenna operating frequency in two different operating bands for satellite or space application. The antenna gain is $3.6 \mathrm{dBi}$ for downlink resonant frequency and $4.7 \mathrm{dBi}$ for uplink frequency application. In $\mathrm{E}$ plane, simulated far-field radiation patterns have been obtained at several frequencies and at the frequency of $6.15 \mathrm{GHz}$ maximum radiations are directed normal to patch geometry and shape of patterns is more or less similar to a dumble shape and semi hemispherical shape. This antenna is specifically designed for satellite communication systems. The frequency range of $3.4-4.2 \mathrm{GHz}$ is used for Fixed Satellite Service (FSS) and broadcast satellite service (BSS) downlinks, Whereas $5.9-6.4 \mathrm{GHz}$ frequency band is used for the FSS/BSS uplinks [8].

We can also improve or enhance the bandwidth of the proposed antenna in future to perform in a wider frequency band.

\section{Acknowledgments}

The authors are thankful to IJSR Journal for the support to develop this document.

\section{References}

[1] C. A. Balanis, Antenna theory: analysis and design. Hoboken, NJ: Wiley Interscience, 2005.

[2] David M.Pozar,Daniel H.Schaubert, IEEE Antennas and Propagation Society. "Microstrip Antenna: The analysis and design of Microstrip antenna and arrays". Willey-Default, 1995.

[3] J. T. Bernhard, Reconfigurable Antennas. Morgan \& Claypool Publishers, 2007.

[4] Hattan.F.Abutarbaush,"Fixed and Reconfigurable Multiband Antenna",July 2011.

[5] K. A. Obeidat, B. D. Raines, R. G. Rojas, and B. T. Strojny, "Design of frequency reconfigurable antennas using the theory of network characteristic modes," IEEE Transactions on Antennas and Propagation, vol. 58, no. 10 , pp. $3106-3113,2010$

[6] H. Elsadek and D. Nashaat, "Multiband and UWB VShaped Antenna Configuration for Wireless Communications Applications," IEEE Antennas and Wireless Propagation Letters, Vol. 7, pg. 89-91, 2008.

[7] H. Elsadek and D. Nashaat, "Multiband and UWB VShaped Antenna Configuration for Wireless Communications Applications," IEEE Antennas and Wireless Propagation Letters, Vol. 7, pg. 89-91, 2008.

[8] Chandrappa D.N., Mrs.Vani R.M. and P.V. Hunagund, "Design and Implimentation of Slotted Reconfigurable Microstrip Antenna for Wireless Application", International Journal of Electronics and Communication Engineering, Vol. 6, No. 3, 2013, pp. 233-239

[9] Hesham A. Mohamed, Heba B. El-Shaarawy, Esmat A. Abdallah, and Hadia El-Hennawy, "Compact Recon ${ }^{-}$gurable Dual Mode Resonator with Switchable Band Using RF PIN Diodes", PIERS Proceedings, Stockholm, Sweden, Vol 3 No. 5 Aug. 2013, pp 10721076.

[10] Symeon Nikolaou, Ramanan Bairavasubramanian, Cesar Lugo, "Pattern and Frequency Reconfigurable Annular Slot Antenna Using PIN Diodes", IEEE transactions on antennas and propagation, vol. 54, no. 2, february 2006, , pp 439-448

[11]Damiano Patron and Kapil R. Dandekar, "Planar Reconfigurable Antenna with Integrated Switching Control Circuitry", The 8th European Conference on Antennas and Propagation (EuCAP 2014), Vol.9, No.14, 2014 IEEE, 2737-2740.

\section{Author Profile}

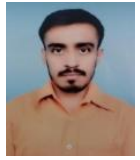

NAMAN MEHROTRA received the B.Tech. Degree in Electronics and Communication Engineering from the University of UTTAR PRADESH, Sultanpur, U.P, in 2013, the M.Tech. Degree in Digital Communication Engineering from the JECRC University, Jaipur, Rajasthan, in 2015. Currently, He is an assistant Professor of Eletronics and Communication Engineering at JECER UDML College of Engineering, Jaipur RTU. His teaching and research areas include antenna system and optical communication 